\title{
OVUM TRANSPORT THROUGH RABBIT OVIDUCTS PERFUSED WITH 6-HYDROXYDOPAMINE
}

\author{
C. A. EDDY* AND D. L. BLACK \\ Laboratory for Reproductive Physiology, \\ Department of Veterinary and Animal Sciences, \\ University of Massachusetts, Amherst, Massachusetts, U.S.A.
}

(Received 15th October 1973)

\begin{abstract}
Summary. Ovum transport was studied at 48,60 and $72 \mathrm{hr}$ post coitum in rabbit oviducts perfused with 6-hydroxydopamine, contralateral control oviducts and oviducts perfused with the vehicle alone. Treatment with 6-hydroxydopamine retarded transport at $60 \mathrm{hr}$ post coitum $(P<0.05)$ but not at 48 or $72 \mathrm{hr}$. No significant difference in ovum transport was seen between control oviducts and those perfused with the vehicle. These results suggest that the influence of adrenergic innervation is time-dependent.
\end{abstract}

The rabbit oviduct receives substantial adrenergic innervation, particularly in the region of the ampullary-isthmic junction and isthmus (Brundin, 1964a, 1965; Owman, Rosengren \& Sjöberg, 1966). It has been suggested that the isthmus acts as an adrenergically controlled sphincter which regulates the passage of ova from the ampulla to the uterus (Brundin, 1964b, c). Although ovum transport is altered by systemic administration of autonomic drugs (Longley, Black \& Currie, 1968; Polidoro, Howe \& Black, 1973), they may produce undesirable side effects. The present study was undertaken to explore further the rôle of the sympathetic nervous system of the oviduct by comparing ovum transport in 6-hydroxydopamine-treated and intact rabbit oviducts.

Sixty adult, oestrous, virgin female rabbits of mixed breeding were divided into six groups of ten animals each. One oviduct of animals in three of the groups received an intraluminal perfusion of $6.0 \mathrm{mg}$ 6-hydroxydopamine (6-OHDA) in ascorbic saline as previously described (Eddy \& Black, 1973). In the animals of the remaining three groups, one oviduct was perfused with the vehicle alone. Contralateral untreated oviducts in all sixty rabbits served as individual controls.

The rabbits were mated 1 week following perfusion and were given 75 i.u. HCG (Sigma Chemical Co.) to ensure the occurrence of ovulation. Two groups of ten animals each, one group composed of those receiving a perfusion of 6-OHDA, the other of those receiving a perfusion of ascorbic saline, were killed at 48,60 and $72 \mathrm{hr}$ post coitum (p.c.). To prevent movement of ova post mortem, the abdomen of each rabbit was rapidly opened immediately after

* Present address: University of Texas School of Medicine at San Antonio, Department of Obstetrics and Gynecology, San Antonio, Texas 78284, U.S.A. 
death and the entire reproductive tract was frozen in situ with isopentane (2methyl butane, Eastman Kodak Co.) cooled with liquid nitrogen (Longley \& Black, 1968). After thawing, the oviducts were trimmed, separated from each uterine horn at the uterotubal junction and divided into ten equal segments. Each oviduct segment and both uterine horns were flushed with $0.9 \%$ saline twice, once in each direction, into watch-glasses and the ova were counted. Ova recovered from the most distal segment (ovarian end) were assumed to have been picked up by the oviduct but not transported; those recovered from

Table 1. Comparison of the ovum recovery from rabbit oviducts perfused with 6-OHDA or the vehicle and the contralateral control oviducts

\begin{tabular}{|c|c|c|c|c|c|}
\hline $\begin{array}{c}\text { Hours } \\
\text { post coitum }\end{array}$ & 6-OHDA & Control & $\begin{array}{l}\text { Ascorbic } \\
\text { saline }\end{array}$ & Control & Mean \\
\hline 48 & $\begin{array}{c}96 \cdot 6 \\
(3 \cdot 00 \pm 0 \cdot 60)^{*}\end{array}$ & $\begin{array}{c}97 \cdot 1 \\
(3 \cdot 40 \pm 0 \cdot 27)\end{array}$ & $\begin{array}{c}100 \\
(3 \cdot 50 \pm 0 \cdot 34)\end{array}$ & $\begin{array}{c}92 \cdot 5 \\
(4 \cdot 00 \pm 0 \cdot 68)\end{array}$ & $96 \cdot 6$ \\
\hline 60 & $\begin{array}{c}89 \cdot 2 \\
(3.40 \pm 0.54)\end{array}$ & $\begin{array}{c}93 \cdot 0 \\
(4.90 \pm 0.71)\end{array}$ & $\begin{array}{c}96 \cdot 8 \\
(3 \cdot 10 \pm 0 \cdot 38)\end{array}$ & $\begin{array}{c}92 \cdot 7 \\
(4 \cdot 10 \pm 0 \cdot 46)\end{array}$ & $92 \cdot 9$ \\
\hline 72 & $\begin{array}{c}66 \cdot 7 \\
(4 \cdot 10 \pm 0 \cdot 74)\end{array}$ & $\begin{array}{c}80 \cdot 0 \\
(4.20 \pm 0.73)\end{array}$ & $\begin{array}{c}84 \cdot 8 \\
(3 \cdot 30 \pm 0 \cdot 45)\end{array}$ & $\begin{array}{c}96 \cdot 6 \\
(2 \cdot 90 \pm 0 \cdot 48)\end{array}$ & $82 \cdot 0$ \\
\hline Mean & $84 \cdot 2$ & $90 \cdot 0$ & 93.9 & $93 \cdot 9$ & $90 \cdot 5$ \\
\hline
\end{tabular}

Values expressed as mean percentage ovum recovery.

* Mean number of ovulations \pm S.E.M.

Table 2. Comparison of the distance travelled by ova in rabbit oviducts perfused with 6-OHDA or the vehicle and in the contralateral control oviducts

\begin{tabular}{|c|c|c|c|c|}
\hline $\begin{array}{c}\text { Hours } \\
\text { post coitum }\end{array}$ & 6-OHDA & Control & Ascorbic saline & Control \\
\hline 48 & $63 \cdot 8 \pm 3 \cdot 03^{a, b}$ & $63 \cdot 9 \pm 2 \cdot 17^{\mathrm{a} \cdot \mathrm{b}}$ & $63 \cdot 4 \pm 1 \cdot 79^{\mathrm{a}, \mathrm{b}}$ & $63 \cdot 7 \pm 1 \cdot 37^{a, b}$ \\
\hline 60 & $48 \cdot 8 \pm 4 \cdot 17^{a}$ & $67 \cdot 5 \pm 1 \cdot 00^{\mathrm{b}}$ & $73 \cdot 0 \pm 2 \cdot 26^{b, d}$ & $66 \cdot 5 \pm 1 \cdot 48^{b}$ \\
\hline 72 & $81 \cdot 7 \pm 5 \cdot 03^{c, d}$ & $96 \cdot 4 \pm 1 \cdot 55^{c}$ & $90 \cdot 7 \pm 2 \cdot 29^{\mathrm{c}}$ & $85 \cdot 7 \pm 2 \cdot 50^{c}$ \\
\hline
\end{tabular}

Values expressed as mean percentage distance travelled \pm S.E.M.

* Means without the same superscript are significantly different $(P<0.05)$.

the uterus were assumed to have been transported $100 \%$ of the length of the oviduct. Ova from segments 2 to 10 were assumed to have been transported 10 to $90 \%$ of the length of the oviduct, respectively. The number of ova recovered from each oviduct and the number of CL on each ovary were used to compute ovum recovery. Ovum transport results were analysed using the analysis of variance and Duncan's New Multiple Range Test.

As shown in Table 1, the method of oviduct segmentation and flushing proved to be an adequate means of determining the position of ova. Ovum recovery for the entire experiment was in excess of $90 \%$.

The data relating to ovum transport through the treated and control oviducts are presented in Table 2. There was no significant difference in ovum transport between control oviducts and those perfused with ascorbic saline. By 
$48 \mathrm{hr}$ p.c., all ova, with a single exception, had entered the isthmus in the control oviducts and those perfused with ascorbic saline; they were located a mean distance of $64 \%$ of the way to the uterus. By $60 \mathrm{hr}$ p.c. they had been transported $69 \%$ and, by $72 \mathrm{hr}$ p.c., they had been transported $91 \%$, of the length of the oviduct.

By contrast, transport through the oviducts treated with 6-OHDA was significantly retarded at $60 \mathrm{hr}$ p.c. $(P<0 \cdot 05)$. By this time, ova had traversed $49 \%$ of the length of the oviducts. At $72 \mathrm{hr}$ p.c., the retarding effect of 6-OHDA was still apparent, although not statistically significant $(P<0 \cdot 10)$. Treatment apparently did not affect transport $(64 \%$ in all oviducts) at $48 \mathrm{hr}$ p.c. In five rabbits, however, one or more ova had not yet entered the isthmus of the treated oviducts; with a single exception, all ova were in the isthmus of the control oviducts and those perfused with ascorbic saline.

If the proposition is accepted that one of the functions of the isthmus is to act as an adrenergically controlled sphincter that regulates the passage of ova, the retarded transport seen following perfusion of 6-OHDA is difficult to explain. Not only was transport retarded at $60 \mathrm{hr}$ p.c., but the position of ova compared with that at $48 \mathrm{hr}$ p.c. strongly suggests retrograde transport. The failure of treatment with 6-OHDA to alter transport significantly at 48 and $72 \mathrm{hr}$ p.c. suggests the existence of additional, possibly time-dependent, factors affecting ovum transport.

Epinephrine has little effect on ovum transport before $60 \mathrm{hr}$ p.c. (Polidoro et al., 1973) but accelerates ovum transport at 60 and $72 \mathrm{hr}$ p.c. (P. Bassignani and D. L. Black, unpublished observations; Polidoro et al., 1973). It is clear from the present study that the effect of 6-OHDA on ovum transport is not uniform but varies with time and presumably with other factors, one of which may be change in the levels of ovarian steroids.

This work was supported in part by NIH Grant No. 06788. The authors gratefully acknowledge the assistance of Dr Richard Damon in the statistical analysis of this study.

\section{REFERENCES}

Brundin, J. (1964a) The distribution of noradrenaline and adrenaline in the fallopian tube of the rabbit. Acta physiol. scand. 62, 156.

Brundin, J. (1964b) A functional block in the isthmus of the rabbit fallopian tube. Acta physiol. scand. 60, 295.

BRUNoIn, J. (1964c) An occlusive mechanism in the fallopian tube of the rabbit. Acta physiol. scand. $61,219$.

Brundin, J. (1965) Distribution and function of adrenergic nerves in the rabbit fallopian tube. Acta physiol. scand. 66, Suppl. 259, 1.

EdDY, C. A. \& BLACK, D. L. (1973) Chemical sympathectomy of the rabbit oviduct using 6-hydroxydopamine. 7. Reprod. Fert. 33,1.

Longley, W. J. \& Black, D. L. (1968) Comparisons of methods for locating ova in the oviduct of the rabbit. F. Reprod. Fert. 16, 69.

Longley, W. J., BlAGK, D. L. \& CurRie, G. N. (1968) Ovarian hormone control of ovum transport in the rabbit as influenced by autonomic drugs. F. Reprod. Fert. 17, 579.

OWman, C., Rosengren, E. \& SJöberg, N. O. (1966) Origin of the adrenergic innervation of the female genital tract of the rabbit. Life Sci. 5, 1389.

Polidoro, J. P., HowE, G. R. \& BLAGK, D. L. (1973) The effects of adrenergic drugs on ovum transport through the rabbit oviduct. 7 . Reprod. Fert. 35, 331. 